\title{
IMPUTABILIDADE PENAL E SANÇÃO À PSICOPATIA: A JURISPRUDÊNCIA DO STJ
}

\author{
CRIMINAL GUILT AND PENALTY TO PSYCHOPATHY: THE \\ JURISPRUDENCE OF STJ
}

\section{Angelo Roberto Ilha da Silva ${ }^{1}$ \\ UFRGS \\ Daison Nelson Ferreira Dias ${ }^{2}$ \\ PUC-RS}

\section{Resumo}

O escopo do artigo é fazer uma apreciação crítica aos acórdãos do Superior Tribunal de Justiça que tratam sobre psicopatia. Examinar-se-á o conceito de psicopatia consoante o entendimento mais atual a partir dos estudos da neurociência, bem como se procederá à verificação das consequências jurídicas diante de comportamentos agressivos praticados por psicopatas. À luz do entendimento viabilizado pelo estudo, uma solução é proposta de lege ferenda.

Palavras-chave

Psicopatia. Jurisprudência. STJ.

\section{Abstract}

1 Professor do Departamento de Ciências Penais da Faculdade de Direito da Universidade Federal do Rio Grande do Sul - UFRGS. Doutor pela Faculdade de Direito da Universidade de São Paulo - USP. Procurador Regional da República na 4a Região. Pesquisador/líder do Grupo de Pesquisa Sistema Criminal Contemporâneo na Perspectiva de uma Interpretação Concretizadora dos Princípios Constitucionais e Garantias Fundamentais UFRGS/CNPq.

2 Mestre e doutorando em Neurociências (Neurologia) pela Faculdade de Medicina da Pontifícia Universidade Católica do Rio Grande do Sul - PUCRS. Bolsista CAPES/PDSE no National Institutes of Health, Bethesda, MD, Estados Unidos da América. Médico neurologista. Pesquisador do Grupo de Pesquisa Sistema Criminal Contemporâneo na Perspectiva de uma Interpretação Concretizadora dos Princípios Constitucionais e Garantias Fundamentais UFRGS/CNPq. 
The aim of this paper is to examine Superior Court of Justice of Brazil decisions on psychopathy. The newest concept of psychopathy is highlighted by the current neuroscientific studies. The Court responses for psychopathic aggressive behavior are examined. As a result, a lege ferenda solution is proposed.

Keywords

Psychopathy. Jurisprudence. STJ

\section{Introdução}

A partir da construção do conceito $^{3}$ dogmático de crime (conduta típica, ilícita e culpável), pode-se afirmar que, tanto a conduta quanto seus predicados, enquanto requisitos do fato punível, funcionam como filtros ao alcance da norma penal. Assim é que um fato para ser considerado uma infração penal deve estar preenchido por todos esses referidos elementos, sendo o último deles a culpabilidade.

Segundo o entendimento mais acatado 4 na doutrina penal, a culpabilidade é o juízo de reprovação que se faz ao agente que tenha praticado um fato típico e ilícito, desde que esse agente seja imputável, tenha o conhecimento ao menos potencial (ou possível) da ilicitude do

3 Este, de forma correta, é o conceito que está em consonância com a doutrina majoritária, o qual designa-se como teoria tripartida, ou seja, considera a culpabilidade como elemento do crime, ao contrário de um setor minoritário, que a considera como "mero" pressuposto de pena. Consulte-se: BIERRENBACH, Sheila. Teoria do crime. Rio de Janeiro: Lumen Juris, 2009, p. 8. Para mais detalhes: SILVA, Ângelo Roberto Ilha da, Da inimputabilidade em face do atual desenvolvimento da psicopatologia e da antropologia. 2a ed. Porto Alegre: Livraria do Advogado, 2015, p. 28-38.

4 Por todos: BRANDÃO, Cláudio. Teoria jurídica do crime. Rio de Janeiro: Forense, 2002, p. 143. 
fato que pratica e seja a ele exigível um comportamento conforme ao direito (não estar sob coação, por exemplo).

Entre imputabilidade (pressuposto, para alguns, ou elemento, para outros, da culpabilidade) e a inimputabilidade (que afasta a capacidade do agente e, por via de consequência também sua culpabilidade) existe uma faixa intermediária, um "meio-termo", que consiste na semi-imputabilidade ou capacidade reduzida, cujas categorias que a preenchem são objeto de controvérsia, dentre as quais é de mencionar-se a psicopatia. Isso porque há autores ${ }^{5}$ que entendem que o psicopata é plenamente imputável, outros ${ }^{6}$ orientam-se pela ideia da semi-imputabilidade em que o psicopata, ante a prática de um fato definido como crime, deveria ter sua pena reduzida e, por fim, um terceiro setor doutrinário ${ }^{7}$ que propugna deva ser submetido à medida de segurança.

A imputabilidade é um status iuris que pode sofrer alterações ao longo das sucessivas avaliações do agente da ação ou omissão sob análise em um dado caso concreto. Uma das grandes dificuldades a ser enfrentada pelo jurista repousa sobre o fato de que as avaliações do estado mental, como regra, são feitas de modo retrospectivo, ou seja, a

5 SILVA, Ângelo Roberto Ilha da; DIAS, Daison Nelson Ferreira. Psicopatas criminosos e a sociedade vulnerável. Porto Alegre: Livraria do Advogado, 2019; SILVA, Ângelo Roberto Ilha da, Da inimputabilidade em face do atual desenvolvimento da psicopatologia e da antropologia. 2a ed. Porto Alegre: Livraria do Advogado, 2015, p. 105; TRINDADE, Jorge; BEHEREGARAY, Andréa; CUNEO, Mônica Rodrigues. Psicopatia: a máscara da justiça. Porto Alegre: Livraria do Advogado, 2009, p. 133.

6 NORONHA, E. Magalhães. Direito penal: Introdução e parte geral. 25a ed. atualizada por Adalberto José Q. T. de Camargo Aranha. São Paulo: Saraiva, 1987, v. 1, p. 165.

7 PIEDADE JÚNIOR, Heitor. Personalidade psicopática, semi-imputabilidade e medida de segurança. Rio de Janeiro: Forense, 1982. 
ação ou omissão prevista pelo legislador está em tempo cronológico diferente daquele no qual incide a avaliação quanto à imputabilidade do agente ao tempo dos fatos sub judice.

Tomada na literalidade, a menção a essa dificuldade não é hábil a esclarecer a imensa gama de contradições aparentes que decorrem de avaliações realizadas em momentos cronológicos distintos. O animus de esclarecer se o agente estava apto a compreender a ilicitude da conduta e a agir de modo a evitá-la pode levar o jurista a confundir avaliações realizadas em momentos distintos, o do fato a ser julgado e o das conclusões periciais, como se representassem a mesma avaliação quanto à capacidade penal.

A compreensão das limitações de interação com o real que decorrem das categorias definidas como doença é uma necessidade que se tornou íntima à própria natureza do legalis opere. Negar essa compreensão é admitir que basta haver uma reclassificação das patologias segundo a discricionariedade das entidades privadas que se dedicam à publicação de classificações de doenças mentais para que ocorra, como consequência, a ressignificação do que fora previsto pelo legislador como exceção à imputabilidade e do que repousa como matéria consolidada no labor jurisprudencial.

A tensão que se estabelece entre as diferentes perspectivas de análise do sujeito se intensifica quando a valoração oscila entre a atribuição de maior peso ao diagnóstico e a atribuição de maior peso ao comportamento efetivamente verificável no caso concreto.

Os estudos mais vanguardistas esclarecem a questão quanto as características da psicopatia. Cumpre destacar que psicopatia e psicopatologia não são sinônimos. O conceito de psicopatia, com ampla documentação, foi desenvolvido em obra de nossa autoria, intitulada 
Psicopatas criminosos e a sociedade vulnerável, da qual colacionamos ${ }^{8}$ a seguinte passagem:

A característica fundamental da psicopatia é o afeto indiferente, a ausência de empatia. É a incapacidade de o sujeito se identificar com o outro cuja condição é sôfrega, em especial quando a condição de sofrimento é imputada pela própria pessoa do psicopata.

A psicopatia é a ruptura intrassubjetiva com os elementos que constituem a suscetibilidade do próprio sujeito em acolher os padrões culturais de desenvolvimento da vida humana. Não há os sintomas típicos dos transtornos de personalidade. Não há a incidência de alterações da sensopercepção. O psicopata não tem alucinações, não tem ilusões, não tem delírios.

No entanto, as expressões emocionais no psicopata são mimetizadas conscientemente, ou seja, o sujeito tem de aprender a copiar as expressões emocionais (tristeza, alegria, etc.) para poder representa-las. Sua constituição subjetiva não evolui com essas expressões. As emoções não são suficientes para modificar o comportamento do psicopata. As experiências afetivas das outras pessoas não o sensibilizam. No entanto, o sujeito não sente ter um prejuízo causado por essa falta de sensibilidade. Não há sofrimento psíquico para o psicopata em razão de não se emocionar.

Nesse contexto, a produção de provas da capacidade penal do sujeito da investigação, ou do acusado propriamente, tem de ser criteriosa e ter a sensibilidade necessária para isolar cronologicamente as ações escrutinadas a fim de estabelecer a cadeia de fatos contra a

8 SILVA, Ângelo Roberto Ilha da; DIAS, Daison Nelson Ferreira. Psicopatas criminosos e a sociedade vulnerável. Porto Alegre: Livraria do Advogado, 2019, p. 97. 
qual se sobreporá a sequência de avaliação do estado mental daquele que sofre a persecutio criminis.

O objetivo desse artigo é revisar a jurisprudência do Superior Tribunal de Justiça em material atinente especificamente ao instituto da psicopatia.

\section{Psicopatia: diagnóstico ou conceito?}

As primeiras utilizações do termo psicopatia foram empregadas para fazer referência às alterações de comportamento sem uma definição específica de associação a um tipo particular de doença mental. Há uma restrição prática para que a psicopatia seja um diagnóstico: a maioria dos psicopatas não será descoberto como tal até que cometa uma infração passível de sanção de natureza penal. Diagnóstico orienta a compreensão no sentido de que psicopatia seja uma doença e conceito, como antítese, orienta à compreensão de que se trata de uma característica do comportamento e não significa doença ou transtorno. Há muito o que discorrer sobre essas duas concepções, mas afirmamos se tratar de um conceito, entre outras razões, porque a psicopatia não é considerada um problema em si mesma até que culmine no prejuízo ao próprio sujeito ou a um terceiro. Isso significa dizer que a pessoa pode ser psicopata, viver a sua vida inteira sem nenhum problema legal ou social maior e nunca ser descoberta pela medicina, pelas ciências da saúde ou pelo direito. Tendo em vista os limites e o propósito deste artigo, remetemos o leitor, a propósito de uma definição mais exaustiva e detalhada, à obra Psicopatas Criminosos e a sociedade vulnerável.

\section{Elementos da vida de relação do psicopata}


Em nota de rodapé, Jonah Lehrer explica em seu best seller Proust foi um neurocientista: como a arte antecipa a ciência, " "O maior fracasso da frenologia foi a incapacidade de assimilar dados que não correspondiam às suas previsões. Por exemplo, ao medirem o crânio de Descartes, os frenólogos encontraram uma testa extremamente pequena, que indicava 'faculdades lógicas e racionais limitadas'. No entanto, em vez de duvidarem das próprias hipóteses, os frenólogos satirizaram Descartes de declararam "que ele não era um pensador tão extraordinário quanto fora considerado". Com espírito crítico, e com a atenção sobre as evidências, cabe destacar alguns dos aspectos da vida do psicopata à luz do que as pesquisas em diversos centros diferentes têm esclarecido há décadas.

O primeiro caso reportado de psicopata no comando de uma corporação foi descrito por Clive Boddy, em 2015. Boddy estuda liderança e realizou sua pesquisa avaliando o desempenho de empregados submetidos às ordens de dois diretores geral diferentes: o primeiro considerado um líder transformador e o segundo considerado um psicopata - segundo os critérios do instrumento de pesquisa denominado Psychopathy Measure-Management Research Version 2 (PM-MRV2). Esse estudo de caso realizou a observação do diretor psicopata ao longo de dois anos. Os fatos descritos por Boddy nesse estudo dão conta de esclarecer o efeito devastador que a liderança de um psicopata sobre uma instituição de caridade na Inglaterra teve. Os empregados relatavam uma falta de líder no sentido de serem deixados à própria sorte, sem receber orientações ou esperanças quanto ao futuro de suas carreiras na organização. Além disso, eles não recebiam metas e objetivos que estivessem alinhados com o sucesso da ciência. Rio de Janeiro: BestSeller, 2010, p. 23. 
instituição a longo prazo. Os empregados não tinham direito de expressar contribuições sob o comando do chefe psicopata. Como não recebiam orientações, os empregados foram progressivamente deixando de saber o que deveriam fazer em suas próprias posições o que culminou com $86 \%$ dos empregados deixando a instituição no período de 2 anos e com uma renovação de quadro que superou os $100 \%$ em três anos porque muitos dos substitutos também se demitiram.

Além de estudos que avaliam o desempenho de psicopatas na chefia de organizações, há pesquisas sobre psicopatas nas atividades industrial e política. Entre as pesquisas de Paul Babiak, destaca-se o estudo realizado a fim de esclarecer três questões: 1) pode acontecer de um sujeito com tendências psicopáticas ser admitido por uma organização industrial? 2) Que tipo de organização, se existir, poderia atrair um psicopata? 3) um sujeito com personalidade psicopática poderia ser bem-sucedido na indústria? Babiak destaca que os profissionais de recursos humanos não são treinados para identificar esses profissionais e que as possibilidades de um psicopata entrar na indústria é aumentada por conta da habilidade de eles enganarem. A hipótese mais aceita é a de que, em geral, a baixa tolerância à frustração e à rotina favorece a atração por atividades de maior risco e de crescimento rápido, como a atividade empresarial e os negócios com tendência ao crescimento rápido e à mudança de características de mercado. Quanto a possibilidade de ter sucesso na atividade industrial, Babiak destaca que o psicopata tem aumentada a sua ansiedade em ambientes industriais porque eles são organizados e restritos. Desse modo, a adaptação não prescinde da situação de caos. $\mathrm{O}$ modelo apresentado sugere que num contexto de uma organização rumando com mudanças caóticas os psicopatas industriais usam suas capacidades de manipulação para gerir de modo efetivo as diferenças entre os 
pontos de vistas dos apoiadores e dos detratores obtendo, assim, sucesso na progressão de suas carreiras. ${ }^{10}$

A previsibilidade quanto ao comportamento que se traduz por infração da lei penal pode ser difícil mesmo considerando os aspectos genéticos. Alejandro Hernandez Dorta e Iván González González apresentaram o pôster EV0946 no 25th European Congress of Psychiatry, que ocorreu em Florença, em abril de 2017, documentando o caso de irmãos gêmeos em que apenas um deles era psicopata criminoso. Os pesquisadores descrevem os jovens como filhos de uma família bem estruturada, de classe média alta, sem histórico de criminalidade ou de doenças mentais. Além disso, destacam a elevada inteligência do irmão não psicopata. Aos 18 anos, o gêmeo psicopata foi para a penitenciária por tráfico de drogas, roubo e múltiplas agressões.

Por outro lado, é fundamental destacar que muito embora haja longa tradição de pesquisas apontando a psicopatia como fator de risco para comportamento malsucedido, existe uma consistente corrente de conhecimento clínico que vincula a psicopatia a um comportamento socialmente bem-sucedido em vários campos, incluindo o mundo dos negócios, a política e a vida cotidiana. Um grande grupo de pesquisa, utilizando fonte de dados dos EUA e do Reino Unido sobre o desempenho dos presidentes norte-americanos, avaliaram o desempenho dos chefes do executivo: as 10 dimensões de avaliação foram desempenho no trabalho de modo geral, capacidade de

10 BABIAK, Paul. When Psychopaths go to Work: A Case Study of an Industrial Psychopath. Reino Unido: Applied Psychology, 1995, 44(2), p. 171: "Although previous research on psychopathic populations in clinical and penal settings suggests that they lead unsuccessful lives, a case study is presented as an example of a successful industrial psychopath." 
persuasão pública, manejo de crises, autoridade moral, gestão econômica, relações internacionais, habilidade administrativa, relações congressionais, definição de uma agenda e busca de justiça igualitária.

Um dos aspectos frequentemente abordados na psicopatia como controvérsia quanto à imputabilidade do agente está relacionado ao problema jusfilosófico da moral.

Os autores escreveram um trabalho original em que apresentam duas hipóteses de pesquisa: a primeira hipótese é a de que as decisões do psicopata bem-sucedido não são éticas; a segunda hipótese é a de que o psicopata bem-sucedido consegue tomar decisões conscientes que contrariam a sua moral interna. Gregory Stevens, Jacqueline Deuling e Achilles Armenakis defendem em seu artigo Successful psychopaths: Are they unethical decision-makers and why? que o psicopata não se desvincula de seu padrão de moralidade interna em si, mas sim de sua compreensão cognitiva da realidade, podendo redefinir o certo e o errado. Além disso, explicam que o psicopata pode saber que fraude é errado em sentido racional puro e, por meio do desengajamento moral, estar apto a redefinir a fraude utilizando alguma combinação de mecanismos de justificação de um ato pessoal com consequências insignificantes.

Estudos realizados com psicopatas em populações não-forenses, apontam para um equilíbrio entre as características da personalidade de modo que o sujeito consegue evitar os aspectos antissociais ou criminais da psicopatia que conduzem a institucionalização.

Não é demais recordar que desde o trabalho seminal de Cleckley se sabe que a criminalidade não está necessariamente associada à psicopatia. As ações antiéticas, mas que estão relacionadas a condutas que não chegam a caracterizar tipos penais compreendem desde o uso abuso de álcool seguido de violência até más condutas 
acadêmicas. Nas atividades empresariais, a psicopatia está relacionada ao aumento de fraudes e de liderança irresponsável. Além disso, psicopatas bem-sucedidos são mais propensos a se engajar em crimes de colarinho branco e em agressões relacionais. ${ }^{11}$

\section{A Psicopatia na Jurisprudência do STJ}

A jurisprudência do Superior Tribunal de Justiça apresenta quatro casos mencionando situações em que a psicopatia foi arguida como condição do sujeito processual. À luz da compreensão mais vanguardista e atual sobre o conceito de psicopatia, procede-se à análise dos aspectos principais desses julgados.

i) Primeiro Caso: RHC 8865/PR, Rel. Min. Jorge Scartezzini, julgado em 14/12/1999.

O primeiro caso, originado no Estado do Paraná, sob relatoria do Min. Jorge Scartezzini é o Recurso em Habeas Corpus n. 8.865, julgado em 14 de dezembro de 1999. O paciente fora preso em flagrante delito, sendo que assim constou do acórdão de $\mathrm{HC}$ em referência:

\section{(...)}

Com efeito, verifica-se que o ora paciente Maurício Aparecido de Oliveira foi denunciado por infração ao art.

12, caput, c/c art. 18, III, da Lei n. 6368/76 porque, ao ser

11 Do inglês Relational Agression é um tipo de violência que decorre do prejuízo imposto à alguém em razão de um ataque à sua posição social. 
abordado por policiais trafegando com o veículo de forma suspeita, tentou fugir e jogou, pelo lado do passageiro, um pacote contendo 123 (cento e vinte e três) gramas de "maconha", cuja substância entorpecente trazia consigo para fins de comercialização.

À margem da discussão que se poderia levantar a propósito da adequação do pleito do paciente pelo deferimento da realização de exame toxicológico - que não se destina à avaliação da saúde mental do examinando, mas sim à avaliação quanto à possibilidade de detecção da presença da substância ilícita nos fluidos corporais - o aspecto mais importante a destacar é que não se pode tratar a epilepsia como sinônimo de psicopatia. Os pacientes com epilepsia não são psicopatas. Não há vinculação necessária entre epilepsia e psicopatia.

Com prudência, no entanto, o eminente ministro Scartezzini afastou a discussão em seu voto, afirmando que, textualmente:

Finalmente, quanto à inobservância da psicopatia representada pela epilepsia - que é portador o paciente, cumpre ressaltar a impossibilidade de exame, por esta Corte, de tal alegação. Trata-se de questão não analisada pelo tribunal a quo, cujo exame, em última análise, acabaria por suprimir instância.

O trecho do voto do eminente min. Scartezzini não adentra o mérito das classificações da epilepsia ou da própria psicopatia, mas destaca que esse não fora objeto da análise nas instâncias probatórias competentes.

Destaque-se que o termo psicopatia nesses autos foi utilizado como sinônimo de doença mental, de modo genérico e incompatível com o entendimento contemporâneo. Nesse particular, há de se destacar que o leitor deve ser advertido no sentido de que 
psicopatologia é o termo que define o estudo das doenças da psique, da mente. Desprendida dos conceitos da filosofia metafísica, a psique seria o resultado funcional das estruturas do sistema nervoso central relacionadas com a cognição, com a compreensão dos fenômenos somáticos no processo de interação intra e intersubjetiva. A psicopatia, por outro lado, remanesce com um sentido de alteração na psique, mas não mais associada à ideia de doença como ficaram caracterizadas as classificações das alterações do estado mental que antes eram também nomeadas psicopatia e que, contemporaneamente, compõe institutos nosológicos próprios.

Esse tipo de confusão ainda é bastante comum na literatura não especializada. Com frequência, confunde-se epilepsia e psicopatia no mesmo instituto. Esse é um erro - e afirmamos de forma enfática - que deve ser superado. A epilepsia é um capítulo a parte na medicina contemporânea. Existem diversas formas de epilepsia e o Brasil tem um trabalho desenvolvido na forma da Liga Brasileira de Epilepsia (LBE), cujos pesquisadores Elza Márcia Yacubian, Lécio Figueira Pinto, Márcia Morita e Mirian Fabíola SG Mendes atuaram na Comissão de Consenso da LBE se encarregaram de coordenar a tradução da nomenclatura da International League Against Epilepsy (ILAE). No entanto, cumpre destacar que mesmo no caso das encefalopatias epilépticas, os tipos de alterações neurológicas estão associados a um padrão de comprometimento cognitivo e comportamental que se manifesta de modo contínuo definindo uma piora clínica da qual o paciente dificilmente se recupera integralmente. ${ }^{12}$ Não se confunde o comportamento do epiléptico com

Ingrid E Scheffer, Samuel Berkovic, Giuseppe Capovilla, Mary B Connolly, Jacqueline French, Laura Guilhoto, Edouard Hirsch, Satish Jain, Gary W. Mathern, Solomon L Moshé, Douglas R Nordli, Emilio Perucca, Torbjorn Tomson, Samuel Wiebe, Yue-Hua Zhang, Sameer M Zuberi [Elza Márcia Yacubian, Lécio Figueira 
o comportamento do psicopata. O psicopata não tem crise convulsiva, não apresenta declínio das funções cognitivas em razão de um número frequente de crises que cursam com descargas elétricas anormais em suas redes neurais intracerebrais, não se trata a psicopatia com anticonvulsivantes. Em geral, a epilepsia compromete precisão motora com que se comporta o sujeito enquanto que a psicopatia confere uma precisão ainda mais aguçada pela indiferença afetiva.

\section{ii) Segundo Caso: HC 246.350/RS, Rel. Min. Og Fernandes, julgado em 12/03/2013.}

O segundo caso, em ordem cronológica, é o Habeas Corpus 246.350, originado no Rio Grande do Sul e apreciado pela Corte sob relatoria do Min. Og Fernandes em julgamento proferido no dia 12 de março de 2013.

Após acórdão que denegou a apelação, a Defensoria Pública do Estado do Rio Grande do Sul impetrou HC com pedido liminar em favor de menor submetido à medida socioeducativa de internação, cumulada com tratamento psiquiátrico e médico contra drogadição. A excepcionalidade da medida prevista pelo inc. I do art. 122 da Lei n.

Pinto, Márcia Morita e Mirian Fabíola SG Mendes, tradução] Classificação da ILAE das epilepsias: artigo da posição da Comissão de Classificação e Terminologia da International League against Epilepsy. Acesso em http://epilepsia.org.br/wpcontent/themes/moqueca/docs/Classificação\%20da\%20ILAE\%20das\%20epilepsias \%202017.pdf, p. 19: "Em uma encefalopatia epiléptica, a atividade epileptiforme abundante interfere no desenvolvimento levando a alentecimento cognitivo e, frequentemente, regressão, algumas vezes associados a consequências psiquiátricas e comportamentais. A atividade epileptiforme pode causar regressão em um indivíduo com desenvolvimento normal ou com atraso no desenvolvimento preexistente, que então mostra uma estagnação ou regressão no desenvolvimento." 
8.069/90 foi justificada pelo fato de o menor ter cometido agressões físicas contra o educador configurando ato infracional equivalente aos crimes de lesão corporal e ameaça. $\mathrm{O}$ infrator foi submetido a laudo médico que constatou transtorno de personalidade anti-social em situação gravosa revelada por diversas internações em clínicas psiquiátricas e por mais de 80 atendimentos nos quais ficaram evidentes: reiterado comportamento agressivo, recusa de tomada de medicação e escusa de submissão ao tratamento médico.

O acordão colaciona, ainda, o seguinte trecho:

L. C. N. M. é um paciente agressivo com os demais pacientes internados e com a equipe médica, não se beneficia com as internações, apresenta transtorno de personalidade anti-social - psicopata, portanto sem cura. Disse ainda que essa psicopatia leva o paciente à prática de homicídio porém jamais de suicídio.

A promotoria, atenta, salientou que:

(...) não há nos autos um laudo efetuado por perito oficial atestando que ele possua alguma doença mental que o incapacite de ter consciência da gravidade dos atos que comete. Assim, deve o adolescente ser responsabilizado pelos atos infracionais que pratica, a fim de que se conscientize que sua conduta não é correta (fl. 182 verso), e, sendo assim, necessária e imperiosa a aplicação de medida de proteção, para tratamento médico e psiquiátrico, como efetivamente determinada na sentença, que não merece reparos. "Porém, tal medida não pode ser a única" (fl. 183). Isso porque L. C. N. M. possui uma extensa lista de antecedentes infracionais (contabiliza mais de vinte registros - fls. 189/99) por lesões corporais, danos, furto $\mathrm{e}$ roubo, lhe sendo 
concedidas várias remissões e aplicadas medidas em meio aberto, inclusive com tratamento médico psiquiátrico e para drogadição. (Grifo no original)

Uma vez verificada a condição de psicopata, os fins previstos no art. 1o do ECA demonstram-se dificilmente atingíveis.

No destaque do relator, a ponderação:

Considerando-se que as medidas socioeducativas possuem, além do caráter punitivo, a finalidade de reeducação dos adolescentes infratores, visando a reabilitação social, mediante o despertar do senso crítico acerca da gravidade do ato praticado, bem como de suas consequências, quer no meio social, quer para o próprio adolescente, faz-se necessário que sua fixação se dê de modo a não comprometer o caráter pedagógico da reprimenda, bem como levando em conta as características pessoais de quem deve a elas se submeter, inviável, portanto, a aplicação de pena mais branda.

O benefício não tem o poder de sensibilizar o infrator:

Ao manter a medida extrema, o Tribunal de origem destacou a extensa lista de antecedentes infracionais do adolescente pela prática de atos infracionais análogos a lesões corporais, danos, furto e roubo, já tendo sido beneficiado por várias remissões e cumprido medidas em meio aberto, de forma que a internação se torna a providência mais adequada para o momento, em harmonia com os princípios do Estatuto menorista.

Muito embora, colacionando no voto os trechos em que a avaliação mencionou a ausência de benefício com o tratamento e o reiterado comportamento infracional, houve adição da ementa, em 
tempo, a fim de acrescentar a recomendação de tratamento especializado embora a decisão tenha sido denegatória da ordem de HC.

Nesse julgado, o diagnóstico sobreveio de equipe profissional habilitada e deu conta de registrar que o menor não se beneficiava das investidas terapêuticas. Esse é um elemento central da condição do psicopata. Não há evidência de melhora com os tratamentos farmacológicos ou cognitivo-comportamentais. A forma de manejar a reprimenda as infrações que o psicopata possa cometer não passa pela oferta de uma terapia que seja realmente eficaz simplesmente porque essa terapia não existe.

\section{iii) Terceiro Caso: REsp 1306687/MT, Rel. Min. Nancy Andrighi, julgado em 18/03/2014}

O REsp 1.306.687 representou a irresignação do Ministério Público do Estado do Mato Grosso na busca da interdição de um jovem que, nos termos do relatório da Min. Andrighi, "praticou atos infracionais equivalentes aos crimes tipificados no art. 121, § 2ㅇ, II, III e IV (homicídios triplamente qualificados), dos quais foram vítimas o padrasto, a mãe de criação e seu irmão de 03 (três) anos de idade, e que ostenta condição psiquiátrica descrita como transtorno não especificado da personalidade (CID 10 - F 60.9),". Os votos veiculados no acórdão foram da Min. Andrighi (relatora), do Min. Cueva e Min. Beneti.

$\mathrm{Na}$ instância de primeiro grau, a demanda foi julgada improcedente por não satisfazer os requisitos do art. 1.767 do Diploma Civilista de 2002. Além de constatar a ausências dos requisitos do inc. I do art. 1.767, o juiz provocou a reflexão: "Mas alguém pode ser 
tolhido em seu direito de liberdade somente em razão da potencialidade de vir a cometer crime? Segundo nosso sistema penal, nem os atos de cogitação de crimes, que são mais graves e sérios do que a mera potencialidade são passíveis de punição!”.

Em recurso ao Tribunal Mato-grossense, a decisão de primeira instância foi reiterada com o fundamento de que "Não comprovada a incapacidade da pessoa para gerir atos da vida civil e bens, não há falarse em interdição.”. O fato é que o fundamento para o pleito da interdição intentada pelo Parquet mato-grossense era penal e não cível.

Do voto do Min. Ricardo Villas Bôas Cueva, observa-se a essência dos fundamentos sobre os quais se baseava o Ministério Público do MT:

Noticiam os autos que, em outubro de 2009, o ora recorrente ajuizou a presente ação de interdição de L. M. da S. G., ao fundamento central de que, aproximando-se o termo final da medida socioeducativa de internação que lhe foi imposta - pela prática de atos infracionais análogos ao crime de homicídio -, seria recomendável sua interdição civil e, consequentemente, sua internação em hospital psiquiátrico, haja vista ter sido diagnosticado como portador de transtorno mental.

Em sua peça inicial, aduziu o parquet, após fazer breve narrativa dos atos delituosos praticados pelo então menor - que consistiram no homicídio de sua mãe adotiva, do padrasto e do filho do casal, que à época contava com apenas três anos de idade -, que "o interditando já demonstrou-se capaz de matar por meras contrariedades do cotidiano e matará outras pessoas caso não seja decretada sua interdição e compulsoriamente internado para acompanhamento especializado" (e-STJ fl. 20).

Fundamental destacar que a sanção imposta à luz do Estatuto da Criança e do Adolescente já havia sido cumprida e o interditando 
contava, no momento em que se julgava o Recurso Especial, 23 anos. Na mesma linha das instâncias de primeiro e segundo grau, o Min. Cueva destaca que:

Impõe-se reconhecer, que, no âmbito da ação de interdição, não há - por absoluta incompetência do juízo cível e pela inadequação da via eleita - campo para a pretensão ministerial de ver reexaminados atos infracionais perpetrados pelo interditando no passado e acerca dos quais já houve competente manifestação judicial, inclusive com a imposição da cabível medida socioeducativa de internação.

Revela-se completamente desinfluente para a apreciação do atual estado de saúde mental do interditando revolver indagações acerca do grau de violência dos atos infracionais por ele outrora praticados, da torpeza de seus motivos, de sua potencial reincidência delitiva, da absorção dos efeitos da medida que lhe foi imposta, etc. Tais circunstâncias são de interesse do Direito Penal, nada dizem respeito à interdição civil, mesmo porque não há no ordenamento jurídico brasileiro possibilidade de que alguém seja submetido à internação em nosocômio psiquiátrico judicial pelo só fato de ter sido autor de crimes violentos.

A confusão frequentemente revelada pela máxima crimes com requintes de crueldade são cometidos por doentes mentais foi enfrentada pelo julgador de primeira instância que ao comentar o laudo pericial que recebera aduziu:

Quesitos do Juízo: [iép:

1 - O interditando possui alguma anomalia psíquica e/ou doença mental? (fls. 101). [ispep?

Resposta: Sim, de acordo com sua história e laudos anteriores, ele apresenta sinais sugestivos de perturbação da saúde mental e epilepsia, mas não 
apresenta indícios de retardo mental, demência ou psicose.

Digo eu, embora os peritos tenham respondido SIM a este quesito, fizeram questão de afirmar que assim responderam em razão de sua história, além de terem deixado grafado que o interditando apresenta sinais sugestivos de perturbação da saúde mental.

Ora, pela sua estória, ele já recebeu a "reprimenda legal", ou seja, já ficou internado por três anos, que é o máximo estabelecido no Estatuto da Criança e do Adolescente.

Além disso, sinais sugestivos de doença mental, não podem ser aceitos como certeza de doença mental, além de que os peritos afirmaram que o interditando não apresenta sequer indícios de retardo mental, demência ou psicose.

Apesar disso, o que se verifica é que o interditando tem alguma enfermidade, já que os peritos mencionaram até o CID da doença, além de afirmarem que ele precisa de uma pessoa para acompanhá-lo nos atos da vida civil.

Ocorre que a enfermidade de que trata o inciso I do art. 1.767, há que ser suficiente para tirar do interditando, o necessário discernimento para os atos da vida civil, não bastando qualquer tipo de enfermidade.

Além disso, a "recomendação" médica para que uma terceira pessoa, 'supervisione' o interditando, é somente para os atos da vida civil, ou seja, atos negociais da vida' civil e não em razão da alegada 'potencialidade' dele vir a cometer crimes.

Assim, se a enfermidade do interditando não é suficiente para retirar-lhe o discernimento para os atos da vida civil e também não é ele deficiente mental, conforme exige o inciso I do art. 1.767 do Código Civil, não está ele sujeito à curatela.

Além disso, como determinar o recolhimento do interditando no Hospital Adauto Botelho, destinado a deficientes mentais, se esse não é o caso do interditando e, pior que isso ainda, por quanto tempo ficará ele lá? (...)" (e-STJ fls. 171/173 - grifou-se). 
As preocupações veiculadas pelo julgador são bastante pertinentes. Sinais sugestivos de perturbação da saúde mental e epilepsia sem apresentar retardo mental, demência ou psicose, não são elementos suficientes para convencer quanto à incapacidade civil do interditando. Desde a sentença, o animus de o Ministério Público do Mato Grosso obter uma sanção na forma de medida de segurança consoante dispõe o inc. I do art. 1.767 combinado com o art. 1.777 do Código Civil estava desvelado. No entanto, também estava desvelada a impossibilidade de se coadunar com um ato de interdição sem um diagnóstico a comprovar a incapacidade e, consequentemente, sem que houvesse um parâmetro para revisão quanto à necessidade de internação compulsória uma vez que a condição de saúde mental desde as alegações iniciais não eram graves o suficiente para justificar a interdição civil - razão pela qual não seria a modificação desses sinais sugestivos de perturbação a condição hábil a autorizar a desinstitucionalização do interditado.

As avaliações clínicas, realizadas enquanto cumpria a medida sócio-educativa, muito embora falassem em crise convulsiva esporádica, não explicitou se essas crises convulsivas eram de natureza epiléptica (cabe destacar que nem toda crise convulsiva é de natureza epiléptica). Além disso, o eletroencefalograma não apresentou alterações do traçado, ou seja, não houve evidência de alterações na transmissão da corrente associada ao funcionamento das redes neurais detectável no exame. Isso não descarta a possibilidade de existir um quadro epiléptico, mas nesse contexto, é uma evidencia contrária porque não foi apontado o tipo de crise pela avaliação do neurologista, deixando o interno apenas com o uso das medicações prescritas para o quadro psiquiátrico (psicotrópicos). 
O laudo médico pericial produzido por ocasião do Exame de Insanidade Mental, colacionado no voto do eminente Min. Cueva, é esclarecedor:

O periciado não é portador de nenhuma "doença mental" (psicose, nem demência), não tem nem "Desenvolvimento mental retardado" (não é deficiente mental) e não tem "Desenvolvimento mental incompleto".

É sim, portador de "Perturbação da Saúde Mental", constante em "Classificação Internacional de Doenças", em sua versão de número dez ('C.ID.' 10).

$E$ assim é que, o Periciando, mesmo em virtude das perturbações da sua saúde mental, era (e é) inteiramente capaz de entender o caráter ilícito do fato, e de determinar de acordo com esse entendimento.

Em razão desta "Perturbação da Saúde Mental", à época do crime o Periciando NÃO estava privado da consciência do caráter ilícito do seu ato.

Tinha sim, plena consciência da ilicitude do seu ato.

Em razão desta "Perturbação da Saúde Mental", o Periciando NÃO estava privado da possibilidade de agir de modo diverso. O Periciando NÃO era incapaz de determinar-se de acordo com esse entendimento. $O$ Periciando era inteiramente capaz.

Não há nenhum indício que o Periciando tivesse tido: um surto psicótico/convulsão/qualquer equivalente epilético/ou utilizado substâncias psicoativas ao tempo do fato. Ao contrário: ele agiu com uma seqüência lógica e coordenada, tanto para premeditar o crime, quanto para realizar o seu intento, e também para simular um assalto, comprar pão para trazer para o café da manhã, solicitar auxílio do tio, e outros detalhes que podemos observar em toda documentação acostada aos autos e levantadas por nós (atos pré/pós delito) (fls. 85/86). (Grifos no original!)

A perturbação do estado mental aparece nesse contexto como uma definição necessária a ser atribuída a quem comete a infração de 
natureza grave como a que fora cometida pelo interditando. $\mathrm{O}$ termo não descreve propriamente uma doença mental. Aliás, não estão presentes os requisitos como reiterado pelos laudos periciais na fase da institucionalização consequente à medida sócio-educativa e na fase processual civil. No TJ/MT a apelação foi julgada aduzindo, entre outros fundamentos, o que segue:

A pretensão do apelante com a interdição do apelado é a internação dele na ala judiciária do Hospital Adauto Botelho, que como bem salientou o MM. Juiz é destinado aos deficientes mentais, o que definitivamente, está comprovado nos autos que o apelado não é.

Não obstante, as particularidades do caso, ter o apelado praticado ato infracional equivalente ao homicídio contra seus familiares, impor ao apelado uma internação por prazo indeterminado e mesmo ausentes os requisitos legais para tanto, não é aceitável, uma vez que, já cumpriu integralmente a medida sócio-educativa imposta por decisão judicial.

Ao Ministério Público cabe a defesa da sociedade e é o que faz ao promover a interdição do apelado. Cumpre-lhe, contudo utilizarse de outros meios, diante da absoluta ausência dos requisitos para a interdição, e sequer para a medida de segurança caso estivesse sujeito à Lei Penal.

Diante do exposto, nego provimento ao recurso (e-STJ fls. 305/311 - grifou-se).

Ao fazer referência ao voto da Min. Andrighi, o Min. Cueva apontou o que definiu como "duplo equívoco, o que, por si só, revelase capaz de esvaziar toda a sua fundamentação", ou seja, primeiro porque o recorrido não fora diagnosticado como sociopata ou psicopata, mas como portador de transtorno não especificado da personalidade (CID-10 F60.9); e, segundo, porque "não se revela tecnicamente adequado falar em reincidência criminal no caso em 
espécie, haja vista que ao tempo dos lamentáveis atos praticados pelo recorrido era ele menor, portanto, inimputável. O que se tem, em casos tais, como de comezinha sabença, é a prática de ato infracional, jamais de crime.". O Min. Cueva destaca, também, que:

1) não se justifica a promoção, pelo Estado, de verdadeira perseguição a sua pessoa, ancorada, única e exclusivamente, na gravidade da ação delitiva por ele perpetrada enquanto inimputável;

2) a privação de sua liberdade e a sujeição a tratamento psiquiátrico não recomendado pelos peritos, não encontra respaldo na lei ou em qualquer causa supralegal - não devendo ser intentada pelo Parquet,

3) durante os 4 anos da demanda, não houve indícios de reincidência no cometimento de infrações por parte do recorrido;

4) o tempo decorrido desde a extinção da execução de sua reprimenda não trouxe provas de que necessária a interdição e, menos ainda, a internação compulsória em hospital psiquiátrico.

\section{Poena praesupponit culpam}

Em seu voto acompanhando a Min. Andrighi, o eminente Min. Beneti delineia os nortes condutores de seu voto. De um lado, afirma que "3.- Meu voto abstém-se de considerações extra-técnico-jurídicas, de natureza psiquiátrica, sociológica e outras, que restam sob a análise e conclusão por parte de especialistas mais habilitados em aludidos campos do saber, e atém-se, meu voto, aos fundamentos fáticos e jurídicos da matéria submetida ao presente julgamento." e, de outro, afirma que "4.- Os fatos são certos. O menor matou a facadas o padrasto, a mãe de criação e um irmão criança de três anos. A perícia psiquiátrica conclui por periculosidade, capaz de leva-lo a repetir atos como os praticados. Do ponto de vista fático, absolutamente necessária 
a internação após a maioridade, para que pessoas absolutamente inocentes não venham a ser atingidas pelo agir descontrolado de freios psicológicos."

Ocorre que o Min. Beneti cita os precedentes do HC 169.172SP, Rel. Min. Luis Felipe Salomão e HC 135.271-SP, de sua própria relatoria, em que $3^{\mathrm{a}}$ e $4^{\mathrm{a}}$ Turmas do STJ unificaram o entendimento de que "A internação compulsória em sede de ação de interdição, como é o caso dos autos, não tem caráter penal, não devendo ser comparada à medida de segurança ou à medida socioeducativa a que esteve submetido no passado o paciente em face do cometimento de ato infracional análogo a homicídio e estupro. Não se ambiciona nos presentes autos aplicar sanção ao ora paciente, seja na espécie de pena, seja na forma de medida de segurança" (HC 169.172-SP, Rel. Min. LUÍS FELIPE SALOMÃO). Com a devida vênia ao eminente Min. Beneti, examinar as diferenças quanto ao elemento subjetivo do tipo é examinar matéria técnica-jurídica. Sob argumento da periculosidade, avaliados os fatos cometidos por inimputável, a prevalecer esse entendimento, não haveria limite nem mesmo quanto à aplicação das medidas sócio-educativas previstas pelo ECA. A matéria deste REsp é singela: não havia diagnóstico de psicopatia e as medidas justificadas como aplicáveis à psicopatia foram instituídas em razão dos atos infracionais praticados e para os quais as sanções previstas já haviam sido cumpridas.

A Min. Andrighi proferiu voto no qual fez um breve apanhado doutrinário a respeito do instituto da sociopatia e da psicopatia. Admitindo que há consenso quanto ao fato de que os psicopatas não respondem ao tratamento nem por medicamentos nem por psicoterapia, a Min. Andrighi argumenta: "19. Note-se, não se extrai do excerto transcrito uma necessária vinculação entre a sociopatia e o cometimento de crimes, mormente crimes violentos como os que 
deram ensejo à internação do recorrido, mas exsurge das colocações, inevitável associação a situações símeis que pululam a memória nacional e também internacional, como o recente caso ocorrido nas cercanias de Brasília, onde uma pessoa, presa pela prática de violência sexual contra duas crianças, alçou a liberdade condicional após 04 (quatro) anos de reclusão para, em uma dantesca sequência criminal, estuprar e matar pelo menos mais seis menores."

Há claramente declinada a preocupação com a defesa social. O pressuposto de que a violência outrora exercida se repetirá está presente no seguinte trecho do voto da relatora:

25. Tanto na hipótese do apenamento quanto na medida socioeducativa - ontologicamente distintas, mas intrinsecamente iguais - a repressão do Estado traduzida no encarceramento ou na internação, apenas postergam a questão quanto à exposição da sociedade e do próprio sociopata à violência produzida por ele mesmo, que provavelmente, em algum outro momento, será replicada.

26. Frise-se, aqui, esse aspecto, pois na atual evolução das ciências médicas não há controle medicamentoso ou terapêutico para essas pessoas e, como dito anteriormente, a reincidência comportamental é quase uma certeza." (Grifo no original!)

Seguindo essa racionalidade, o psicopata seria uma espécie para a qual não haveria tipos diferentes de sanções em função dos diferentes tipos penais ou infracionais definidos pelo legislador. Senão vejamos, os seguintes argumentos da Min. Andrighi:

27. Assim, em uma apreciação axiológica do problema, opõe-se à liberdade desses indivíduos, após o cumprimento da pena, da medida de segurança, ou da 
medida socioeducativa, à legítima aspiração da sociedade de que não seja exposta a uma situação que provavelmente engendrará novos rompantes de violência e agressão.

(...)

29. Como visto no arcabouço teórico anteriormente delineado, a atuação do sociopata ou psicopata não é conceitualmente estática, ou dinamicamente previsível, circunstância que cria zona gris sem previsão específica, que leva o julgador à encruzilhada, sinalada, à destra, pela busca de solução técnico-jurídica plausível, e possível, para a hipótese e, a vezo, pelo mero lavar as mãos diante de enredo previsível e vaticinado, de nova tragédia social.

(...)

53. A ausência dos freios de moral e ética sociais devem tornar o psicopata alvo de especial atenção estatal, para que tenha um acompanhamento médico e psicológico intensivo e contínuo, tal como ocorre com outras condições geradoras de enfermidade ou deficiência mental, episódica ou perene.

Um dos problemas a ser enfrentado por essa perspectiva é que as razões pelas quais a Lei Federal n. 10.216, de 06 de abril de 2001 dispõe sobre o direito de as pessoas portadoras de transtornos mentais receberem assistência de saúde mental notadamente em razão da previsão do direito social à saúde previsto na Constituição Federal de 1988 e das dificuldades com as internações com as quais os pacientes não concordavam desde que se instituíram os movimentos antimanicomiais. A contrario sensu, nessa ratio decidendi, o uso da legislação sanitária não serve para que se opere a proteção ao interditado, mas para que se protege a sociedade hipoteticamente em risco. $\mathrm{O}$ aspecto ainda mais gravoso nessa hipótese é o de que nos casos 
em que não há terapia com eficácia reconhecida - seja farmacológica, seja cognitivo-comportamental - a institucionalização do interditado é medida que não contrapõe nenhuma ação estatal à subtração da liberdade da pessoa. Por essas razões, essa medida não pode ser instituída sem que tenha havido efetivamente uma lesão a bem jurídico tutelado pelo ordenamento jurídico-penal brasileiro.

Além disso, a matéria carece de maior esclarecimento. $\mathrm{O}$ voto da Min. Andrighi traz, ainda, duas assertivas que merecem ser esclarecidas:

39. Reforça-se, aqui, que as ações de indivíduos psicóticos não se restringem a crimes de grande repercussão, mas usam sua peculiar condição para transigirem com o correto, no cotidiano profissional, familiar e nas demais relações cíveis afetas a todos os indivíduos. e

55. Em diversas dessas situações, a pessoa apresenta plena lucidez e, consequentemente capacidade civil, mas por vício, ato volitivo desestruturado por mal de qualquer natureza, ou surto psicótico, esporadicamente se abrem janelas que levam ao maltrato de sua própria pessoa, ações violentas e, em grau secundário descuido com as suas relações cíveis.

Psicopata e psicótico não são sinônimos. O psicótico é o sujeito cuja percepção da realidade está alterada comumente apresentando um quadro alucinatório associado, como enxergando pessoas que já morreram ou pessoas que ninguém mais enxerga num dado recinto; como ouvindo vozes de pessoas que já morreram, que nunca existiram ou que mais ninguém está ouvindo. $\mathrm{O}$ psicopata não tem esse tipo de alteração sensoperceptiva. O ponto central do argumento da Min. Relatora, entretanto, é declinado ao final do voto: 
58. A sociopatia, quando há prévia manifestação de violência por parte do sociopata, demonstra, inelutavelmente, percepção desvirtuada das regras sociais, dos limites individuais e da dor e sofrimento alheio, condições que apesar de não infirmarem, per se, a capacidade do indivíduo gerenciar sua vida civil, por colocarem em cheque a própria vida do interditando e de outrem, autorizam a curatela do indivíduo para que esse possa ter efetivo acompanhamento psiquiátrico, de forma voluntária ou coercitiva, com ou sem restrições à liberdade, a depender do quadro mental constatado, da evolução - se houver - da patologia, ou de seu tratamento.

iv) Quarto Caso: HC 308246/SP, Min. Nefi Cordeiro, julgado em 24/02/2015.

Habeas Corpus substitutivo de recurso aos tribunais superiores, foi examinado quanto à existência de ilegalidade flagrante, abuso de poder ou teratologia - as quais afastadas, ensejaram o não conhecimento do remédio constitucional. $\mathrm{O}$ paciente postulava progressão de regime que desconsiderasse as conclusões do exame criminológico - uma vez que o benefício fora indeferido pelo juízo de execução após a constatação de que:

É que, malgrado tenha o sentenciado obtido atestado de ótimo comportamento carcerário (fl. 16), não há se falar em preenchimento do requisito subjetivo.

Com efeito, não há nos autos elementos sólidos que permitam concluir que ele faça jus à progressão pretendida, com projeção 
de juízo razoavelmente seguro quanto ao seu não retorno à delinquência e ao cabal cumprimento da pena.

$E$, consoante se depreende das conclusões externadas pelos experts que o avaliaram, isto é, a assistente social, a psicóloga e $o$ psiquiatra, emerge evidente que, de fato, o agravante ainda não reuniu mérito para a progressão de regime, sobretudo porque os peritos foram uníssonos ao concluir que ele sequer assume os delitos que cometeu.

Ainda, a psicóloga relatou que ao longo da entrevista ele apresentou um discurso contraditório, sugestivo de dissimulação e indícios de déficit cognitivo: (...) Ao falar do delito foi evasivo e contraditório. Primeiro negou que tenha praticado o crime; continuou: "eu sou cúmplice porque o dia em que iam fazer isso com a menina eu ouvi. Eu não fiz, mas se estão falando que eu fiz, eu fiz!"

Afirmou, ainda, que ele aduziu que está preso por não terem encontrado a pessoa que cometeu a crueldade. Tem planos inconsistentes para o futuro (fls. 25/29)

$E$ acrescentou a expert que o sentenciado, durante a entrevista não se mostrou capaz de elaborar uma crítica adequada sobre os delitos e nem foi capaz de assumir a responsabilidade que lhe cabe diante de tais atos. Não esboçou nenhum sentimento de culpa ou remorso pela barbárie cometida e demonstrou comprometimento de suas funções psíquicas, inclusive com funcionamento da memória prejudicada (sic), tendo concluído, de modo claro e direto, que ele não tem condiçôes de beneficiarse da progressão ao regime semiaberto.

Não bastasse, na mesma direção relatou o psiquiatra que também o examinou, enaltecendo que há forte indício de transtorno de conduta em adolescente, firmado de forma mais intensa na idade adulta, com diversos conflitos com a Lei. Estes trazem diversos elementos sugestivos de transtorno de personalidade antissocial (CID 10 F60. dois). Neste caso, dentro das diversas avaliações realizadas, observa-se a persistência de quadro de descrição dos fatos de forma indiferente, sem crítica construída sobre o evento e sobre os atos delinquenciais, persistindo ainda com elevado 
risco para o envolvimento com ilícitos. Diante do exposto acima, é possível afirmar que o avaliando apresenta quadro de psicopatia (sintomas/sinais de doença mental) compatível com transtorno de Personalidade Antissocial (CID 10 F60. dois), e, no momento, com pouca crítica sobre o fato que gerou a atual prisão. Do ponto de vista psiquiátrico, não está apto para receber o benefício da progressão de pena (sic, fls. 32/33). (Grifos no original)

Nesse caso concreto, o eminente Min. Cordeiro destaca que embora a alteração legislativa promovida pela Lei 10.793/2003 tenha subtraído a obrigatoriedade de realização do exame criminológico, antes previsto no parágrafo único do art. 112 da Lei de Execuções Penais (Lei 7.210/1984), como requisito para a concessão da progressão de regime, "cumpre ao Julgador verificar, em cada caso, acerca da necessidade ou não de sua realização, podendo dispensar o exame criminológico ou, ao contrário, determinar sua realização, desde que mediante decisão concretamente fundamentada na conduta do apenado no decorrer da execução. Assim, uma vez realizado o exame, nada obsta sua utilização pelo magistrado, como fundamento válido para o indeferimento do pedido de progressão de regime, como na espécie."

Em síntese, a ausência do dever de investigar não implica a ausência de considerar o que fora investigado. No caso deste $\mathrm{HC}$, o paciente estava cumprindo pena e o exame criminológico não evidenciou nenhuma mudança quanto à crítica do apenado quanto às razões pelas quais cumpria a pena.

V. Psicopata: Inimputável, semi-imputável ou imputável? 
Esse questionamento é particularmente importante. Não há, atualmente, nenhum transtorno ou doença mental que configure abstrata e incondicionalmente inimputabilidade ao agente. Ainda que se tratando de pessoa portadora de deficiência, o Estatuto da Pessoa com Deficiência (Lei no 13.146, de 6 de julho de 2015), que nos dá o conceito de pessoa com deficiência na forma do caput do art. 2o, estabelece na forma do $\S 1$ o do art. 2 o que:

§ 1 O $\mathrm{A}$ avaliação da deficiência, quando necessária, será biopsicossocial, realizada por equipe multiprofissional e interdisciplinar e considerará:

I - os impedimentos nas funções e nas estruturas do corpo;

II - os fatores socioambientais, psicológicos e pessoais;

III - a limitação no desempenho de atividades; e

IV - a restrição de participação.

A questão, entretanto, é anterior a este questionamento porque a psicopatia não é um transtorno mental, mas uma condição humana com uma característica que pode conferir uma grande adaptação ao sujeito: a indiferença afetiva.

\section{Considerações Finais}

Não há dúvidas de que o psicopata seja imputável. Os pesquisadores que defendem que o psicopata tem a capacidade de se desengajar dos padrões morais adquiridos ao longo do seu convívio social e de redefinir cognitivamente o que considera certo ou errado de modo desprendido do que esse padrão moral possa definir como certo ou errado, também defendem que o psicopata não possui dificuldades de entender a ilicitude dos seus atos e que muitas das vezes 
atua de modo bastante escorreito para evitar as sanções penais mesmo quando atua de modo antiético ou ilícito.

Há uma questão não respondida pela parcela da doutrina que defende a semi-imputabilidade do psicopata: que sanção deve ser aplicada pelo Estado nos casos em que o autor do fato típico penal é um psicopata? Com certeza não é a medida de segurança. Isso porque a medida de segurança pressupõe que o agente se submeta compulsoriamente a um tratamento que o Estado tem o dever de prover. A oferta de tratamento, portanto, é parte da obrigação estatal. Sem a existência de um tratamento efetivo, não há como sustentar a que a medida de segurança está apta a cumprir a função de propiciar as condições de sociabilidade ao sancionado. Em suma, aplicar essa medida a um psicopata seria aplicar uma medida que não realiza os escopos do direito penal.

A jurisprudência do STJ em relação à matéria demonstra a dificuldade em se lidar com o tema à luz da doutrina. No primeiro caso discutido nesse artigo, o RHC 8.865/PR, Rel. Min. Jorge Scartezzini, julgado em 14/12/1999, a psicopatia é debatida como uma consequência da epilepsia. Esse tipo de associação rotula inadequadamente os milhares de pacientes com epilepsia sob tratamento no Brasil. Não existe nenhuma associação científica entre epilepsia e a psicopatia como conceituada atualmente. Esse tipo de associação está afim a uma literatura científica já superada, muito anterior ao desenvolvimento dos estudos de neuroimagem, da medicina baseada em evidências, do genoma humano, da pesquisa translacional e das contribuições advindas da neurociência do comportamento, por exemplo. Entretanto, dos quatro acórdãos revisados, o RHC 8.865/PR tem a escusa de que, à época do julgamento, os principais conhecimentos que modificaram o entendimento contemporâneo da medicina baseada em evidências ainda eram pouco 
difundidos, no Brasil. No segundo caso, o HC 246.350/RS, Rel. Min. Og Fernandes, julgado em 12/03/2013, o remédio constitucional foi denegado em razão de o laudo apontar transtorno de personalidade antissocial e que "L. C. N. M. é um paciente agressivo com os demais pacientes internados e com a equipe médica, não se beneficia com as internações, apresenta transtorno de personalidade anti-social psicopata, portanto sem cura. Disse ainda que essa psicopatia leva o paciente à prática de homicídio porém jamais de suicídio" (fls. 186/7)." Se o infrator não se beneficia das internações e mantém uma conduta negativa em relação a sua própria parcela de responsabilidade sobre os atos infracionais, o Estado evita um problema fora da instituição a que esse jovem está recolhido, mas mantém um problema em relação às pessoas também recolhidas sob tutela do Estado e/ou que trabalham na mesma instituição.

No terceiro caso, o REsp 1.306.687/MT, Rel. Min. Nancy Andrighi, julgado em 18/03/2014, o problema atinge proporções mais significativas do ponto de vista do Direito Penal. À margem da discussão sobre o Garantismo Penal, há de se destacar que os princípios do Direito Penal foram violados. Isso porque se definiu uma interdição civil cujo objetivo desvelado era promover a institucionalização do interditando baseado exclusivamente em fato pretérito para o qual as medidas sancionadoras cabíveis já haviam sido aplicadas.

No quarto caso, o HC 308.246/SP, Min. Nefi Cordeiro, julgado em 24/02/2015, por outro lado, apontou o exercício adequado da função a que se destina Superior Tribunal de Justiça. Isso porque a fundamentação do Habeas Corpus objetiva fazer o juízo valorar a prova em sentido contrário ao seu próprio significado. A controvérsia pode ser resumida no que se relaciona à existência de um exame criminológico com parecer fundamentado desfavorável à progressão de regime. A defesa fundamentou a desnecessidade de realização de 
exame criminológico desde a reforma instituída pela Lei 10.793/2003, que modificou a redação do art. 112 da Lei de Execuções Penais subtraindo o texto que determinava a realização do referido exame. Ocorre que uma vez realizado, o exame passa a ser prova constituída e, nesse caso, constituiu-se em prova contrária aos pressupostos aptos a facilitar a ressocialização.

Como é consabido, diferentemente do que ocorria em face da sistemática original do Código Penal de 1940, qual seja, no sistema duplo binário, que permitia a cumulação da pena com a medida de segurança, hoje, sob a vigência do sistema vicariante, a consequência para o agente que pratique um injusto penal culpável será a pena criminal. Por outro lado, se este agente praticar um injusto penal não culpável, em virtude de inimputabilidade, ou culpável mas de modo reduzido, ou seja, sendo semi-imputável, em hipóteses em que houver a confluência do parágrafo único do art. 26 com o art. 97, ambos do Código Penal, a consequência será a medida de segurança.

Conforme mencionamos neste artigo, parte da doutrina penal considera o psicopata semi-imputável passível de tratamento, mediante a substituição da pena reduzida por medida de segurança. Porém, tal solução não apresenta qualquer respaldo científico, pois não há tratamento, farmacológico ou não, apto a tratar os psicopatas. Isso porque tais indivíduos não são doentes mentais, porquanto mantêm preservada sua cognição e sua autodeterminação, até mais do que as pessoas não psicopatas. $\mathrm{O}$ afeto indiferente do psicopata o permite que pratique suas ações no campo estritamente racional, sem ser afetado pelos limites impostos pela empatia, o que o coloca numa posição privilegiada. Assim, a única resposta estatal adequada diante de uma infração penal praticada por um psicopata é a pena criminal.

De lege ferenda, sugere-se que os condenados psicopatas venham a cumprir suas penas em estabelecimentos prisionais 
apartados daqueles destinados a condenados não psicopatas, de modo a impossibilitar a subjugação destes últimos. Como o psicopata, quando criminoso, pratica o fato punível por algum motivo, e não de forma gratuita, a pena criminal, sendo efetiva, e, tendo em vista sua postura eminentemente racional, pode vir a dissuadi-lo da opção delitiva pelo simples fato de desejar não vir a ser encarcerado.

\section{Referências}

BABIAK, Paul. When Psychopaths go to Work: A Case Study of an Industrial Psychopath. Reino Unido: Applied Psychology, 1995, 44(2), 171-188.

BIERRENBACH, Sheila. Teoria do crime. Rio de Janeiro: Lumen juris, 2009.

BODDY, Clive R. Psychopathic Leadership A Case Study of a Corporate Psychopath CEO. Holanda: Journal of Business Ethics, 2017, p. 141-156.

BRANDÃO, Cláudio. Teoria jurídica do crime. Rio de Janeiro: Forense, 2002.

Cleckley, Hervey Milton. The Mask of Sanity. Augusta: C. V. Mosby Co, 1988.

DeLisi, Matt. Psychopath as Unified Theory of Crime. Nova Iorque: Palgrave McMillan, 2016, p.

DORTA, Alejandro Hernandez; González, Iván González. Psychopathy and twins. A case report. Pôster EV0946. European Psychiatry Association. França: Elsevier, 2017, S713. 
LILIENFELD, Scott O.; WALDMAN, Irwin D.; LANDFIELD, Kristin; WATTS, Ashley L.; RUBENZER, Steven; FASCHINGBAUER, Thomas R. Fearless Dominance and the U.S. Presidency: Implications of Psychopathic Personality Traits for Successful and Unsuccessful Political Leadership. Journal of Personality and Social Psychology. Washington: APA, 2012, v. 103 (3), 489-505.

NORONHA, E. Magalhães. Direito penal: Introdução e parte geral. 25a ed. atualizada por Adalberto José Q. T. de Camargo Aranha. São Paulo: Saraiva, 1987, v. 1.

PIEDADE JÚNIOR, Heitor. Personalidade psicopática, semiimputabilidade e medida de segurança. Rio de Janeiro: Forense, 1982. SILVA, Ângelo Roberto Ilha da. Da inimputabilidade em face do atual desenvolvimento da psicopatologia e da antropologia. 2a ed. Porto Alegre: Livraria do Advogado, 2015.

SILVA, Ângelo Roberto Ilha da; DIAS, Daison Nelson Ferreira. Psicopatas criminosos e a sociedade vulnerável. Porto Alegre: Livraria do Advogado Editora, 2019.

STEVENS, Gregory W.; DEULING, Jacqueline K.; ARMENAKIS, Achilles A. Successful psychopaths: Are they unethical decisionmakers and why? Journal of Business Ethics, 2012, 105 (2), 139-149. TRINDADE, Jorge; BEHEREGARAY, Andréa; CUNEO, Mônica Rodrigues. Psicopatia: a máscara da justiça. Porto Alegre: Livraria do Advogado, 2009. 